06;09

\title{
Визуализация процесса разрушения материалов при ударном воздействии с помощью механолюминесцирующего покрытия
}

\author{
(C) А.Ф. Банишев \\ Институт проблем лазерных и информационных технологий РАН - \\ филиал ФНИЦ „Кристаллографрия и фотоника“ РАН, Шатура, Московская обл., Россия \\ E-mail: banishev@mail.ru
}

Поступило в Редакцию 16 февраля 2021 г.

В окончательной редакции 9 марта 2021 г.

Принято к публикации 9 марта 2021 г.

Исследовался процесс разрушения материалов при механическом воздействии (ударе). Для регистрации и визуализации процесса разрушения использовался механолюминесцирующий композиционный материал на основе прозрачного в видимой области спектра клея и порошка люминофора, который наносился на поверхность исследуемого материала. Показано, что механолюминесцирующий слой чувствителен к образующимся при ударе трещинам в образце и позволяет с хорошим разрешением визуализировать процесс их образования и роста.

Ключевые слова: композиционный материал, механолюминесценция, разрушение материала, визуализация процесса разрушения.

DOI: 10.21883/PJTF.2021.11.51005.18739

В последние годы возрос интерес к исследованиям механо-пьезо-люминофоров и созданию на их основе новых типов приборов и устройств механо-пьезо-фотоники, в частности механооптических конверторов для контроля состояния материалов, подвергающихся механическим воздействиям [1-6]. Механолюминофоры - это материалы, которые способны люминесцировать при механическом воздействии. За последние 15-20 лет синтезировано большое количество механолюминофоров с высоким выходом механооптического преобразования. Особый интерес представляют механолюминофоры на основе редкоземельных элементов [1,7-9]. Это, как правило, мелкодисперсные порошки, полученные методом высокотемпературного спекания оксидов различных элементов, в состав которых входят редкоземельные элементы, которые являются центрами фотолюминесценции и механолюминесценции. Установлено, что ярко выраженными свойствами механолюминесценции обладают механолюминофоры, кристаллическая структура которых не имеет центра симметрии. В частности, высокой эффективностью механооптического преобразования обладает люминофор $\mathrm{SrAl}_{2} \mathrm{O}_{4}: \mathrm{Eu}^{2+}, \mathrm{Dy}^{3+}[1,3,7,10,11]$. Центрами фотолюминесценции, фосфоресценции и механолюминесценции в этом люминофоре являются ионы европия $\left(\mathrm{Eu}^{2+}\right)$. Введение диспрозия $\left(\mathrm{Dy}^{3+}\right)$ в кристаллическую решетку значительно повышает люминесцентные характеристики люминофора. Считается, что электронные уровни ионов $\mathrm{Dy}^{3+}$ образуют в запрещенной зоне кристалла электронные ловушки. При термоактивации ловушек $\left(\mathrm{Dy}^{3+}\right)$ происходит передача накопленной на них энергии центрам люминесценции $\left(\mathrm{Eu}^{2+}\right)$, что обеспечивает длительное послесвечение (фосфоресценцию) люминофора. Возможные механизмы длительного послесвечения люминофора многократно обсуждались в разных работах [1,8-12].

При механическом воздействии (деформации материала) вероятность активации ловушек возрастает за счет смещения электронных уровней ловушек из-за их взаимодействия с наведенными при деформации локальными пьезоэлектрическими полями. Механолюминесценция люминофора $\mathrm{SrAl}_{2} \mathrm{O}_{4}: \mathrm{Eu}^{2+}, \mathrm{Dy}^{3+}$ связана со смещением электронных уровней ловушек при деформации материала. Таким образом, центрами фотолюминесценции, термолюминесценции и механолюминесценции являются ионы $\mathrm{Eu}^{2+}$, однако механизмы возбуждения разные.

В настоящей работе получен композиционный механолюминесцирующий материал на основе прозрачного в видимой области спектра клея и порошка люминофора $\mathrm{SrAl}_{2} \mathrm{O}_{4}: \mathrm{Eu}^{2+}, \mathrm{Dy}^{3+}$. Исследовался процесс разрушения стеклянных пластин марки К8 с использованием полученного механолюминесцирующего композита для визуализации и диагностики процесса разрушения при механическом воздействии (ударе). Исследовались фотолюминесценция и механолюминесценция полученного композита.

Визуализация напряжений, возникающих при ударе, и образующихся трещин (разрушение материала) проводилась с помощью механолюминесцирующего композиционного слоя, нанесенного на тыльную поверхность пластины. Для этого готовилась суспензия на основе прозрачного в видимой области спектра двухкомпонентного клея (смола, отвердитель) и порошка люминофора $\mathrm{SrAl}_{2} \mathrm{O}_{4}: \mathrm{Eu}^{2+}, \mathrm{Dy}^{3+}$. Тонкий слой суспензии наносился на поверхность прозрачной стеклянной пластины диаметром $30 \mathrm{~mm}$ и толщиной $2 \mathrm{~mm}$. После затвердевания суспензии на поверхности стеклянной пластины 


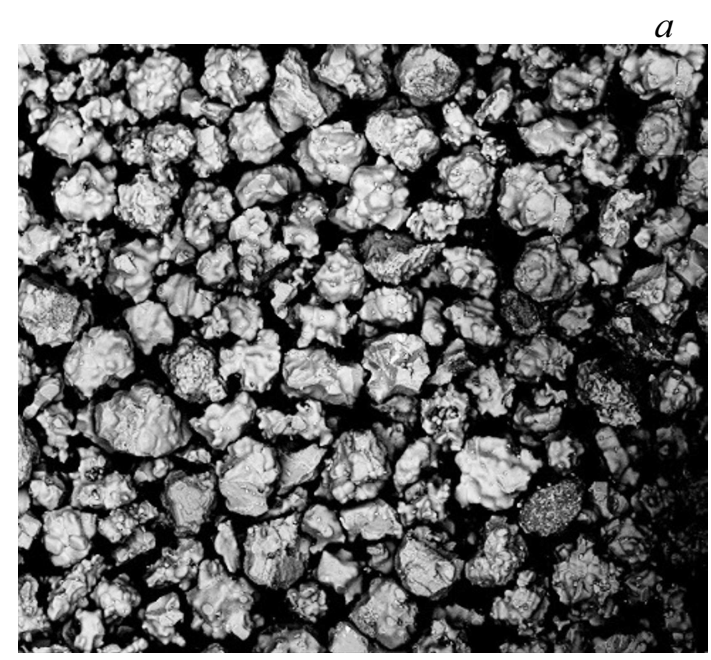

$200 \mu \mathrm{m}$

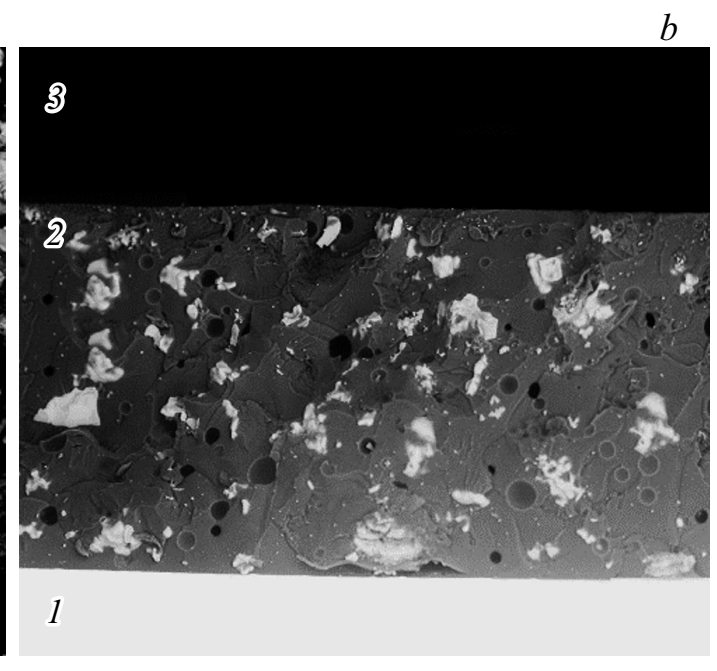

$200 \mu \mathrm{m}$

Рис. 1. $a$ - СЭМ-изображение микрочастиц люминофора $\mathrm{SrAl}_{2} \mathrm{O}_{4}: \mathrm{Eu}^{2+}, \mathrm{Dy}^{3+} ; b-\mathrm{C} Э \mathrm{M-изображение} \mathrm{скола} \mathrm{стеклянной} \mathrm{пластины}$ с нанесенным на поверхности механолюминесцирующим слоем: 1 - подложка из стекла, 2 - композиционный слой, 3 - свободное пространство (вакуум).

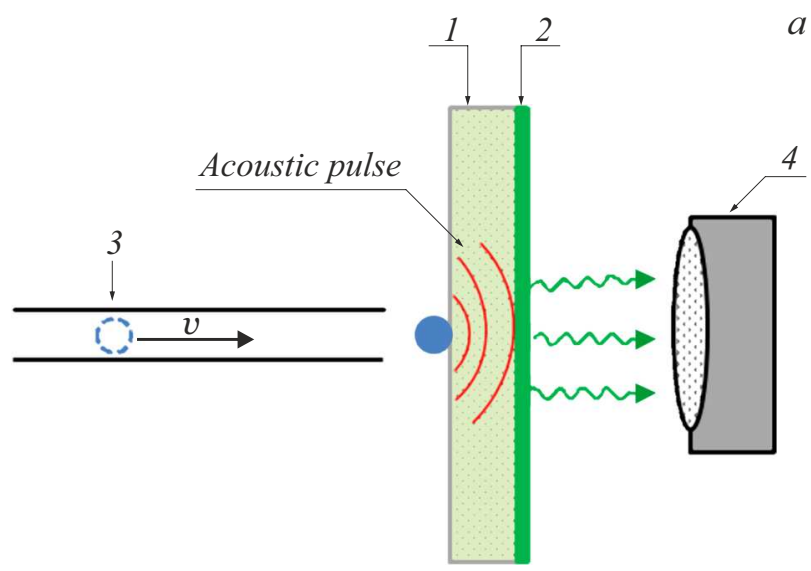

$b$

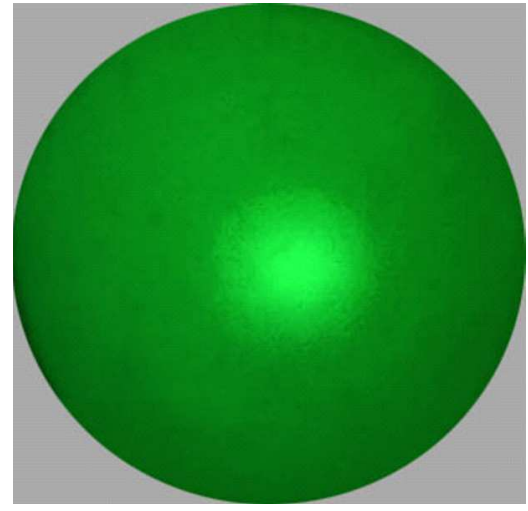

$10 \mathrm{~mm}$
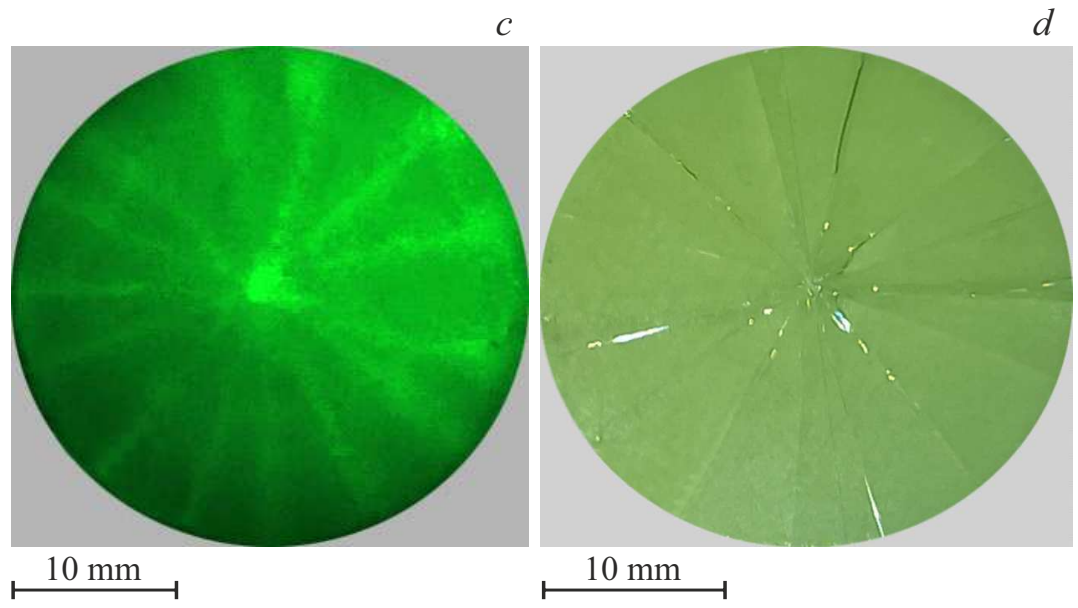

Рис. 2. $a-$ схема экспериментальной установки для исследования процесса разрушения материалов: 1 - пластина из стекла, 2 - механолюминесцирующий слой, 3 - механический ударник, $4-$ видеокамера; $b-d-$ изображения поверхности механолюминесцирующего слоя на стеклянной пластине после удара: $b$ - до порога образования разрушения (скорость шарика $v \approx 1.5 \mathrm{~m} / \mathrm{s}$ ), $c$ - выше порога образования трещин (скорость $v \approx 1.8 \mathrm{~m} / \mathrm{s}$ ), $d-$ изображение свободной поверхности стеклянной пластины после разрушения (образования трещин). 
формировался тонкий слой $(h \approx 370 \mu \mathrm{m})$ композиционного механолюминесцирующего материала. На рис. 1 показаны полученное с помощью сканирующего электронного микроскопа (СЭМ) изображение микрочастиц $\mathrm{SrAl}_{2} \mathrm{O}_{4}: \mathrm{Eu}^{2+}, \mathrm{Dy}^{3+}$, а также СЭМ-изображение скола стеклянной пластины с нанесенным на ее поверхность композиционным механолюминесцирующим слоем.

На рис. 2, а показана схема экспериментальной установки для исследования процесса разрушения материалов. Механический ударник воздействовал на обратную (свободную) поверхность стеклянной пластины. Регистрация свечения механолюминесцирующего слоя, возникающего в результате удара металлического шарика массой $m \approx 3.2 \mathrm{~g}$, осуществлялась с помощью видеокамеры (частота сьемки 30 кадров в секунду). На рис. 2, $b$, $c$ показаны изображения поверхности механолюминесцирующего слоя до порога разрушения стеклянной пластины и после ее разрушения. Свечение (механолюминесценция) композиционного слоя, появляющееся в результате удара металлического шарика, свидетельствует о механических напряжениях, возникающих в стеклянной пластине и контактирующем с ней композиционном слое. На рис. 2, $b$ показано свечение поверхности при силе удара меньше порогового значения, при котором начинается разрушение материала. В этом случае свечение имело форму пятна с максимумом интенсивности в центре. С увеличением расстояния от центра интенсивность свечения быстро падает. Известно [1,7-9,13,14], что интенсивность свечения механолюминесцирующего слоя определяется величиной и скоростью изменения механических напряжений и деформаций, поэтому по временно́му изменению и пространственному распределению интенсивности механолюминесценции композиционного слоя можно судить об изменении и распределении механических напряжений в пластине, возникающих при механическом воздействии. На рис. 2, c сила удара была выше порога разрушения материала (порога образования трещин). В механолюминесцирующем слое появился набор радиально направленных светящихся линий. Осмотр стеклянной пластины показал, что положение светящихся линий точно совпадает с положениями микротрещин и трещин, образовавшихся в пластине в результате удара. При зарождении трещин в результате удара в их вершинах концентрируются значительные напряжения, которые приводят к дальнейшему росту трещин. В местах образования трещин происходит „разделение“ материала, что вызывает растягивающие напряжения в механолюминесцирующем слое. В результате в механолюминесцирующем слое возникают светящиеся линии, положение которых точно совпадает с положениями трещин в стеклянной пластине. На рис. $2, d$ показано изображение свободной поверхности стеклянной пластины после разрушения.

Следует заметить, что некоторые трещины были плохо видны невооруженным глазом и их можно было разглядеть только с помощью лупы или под микроскопом,

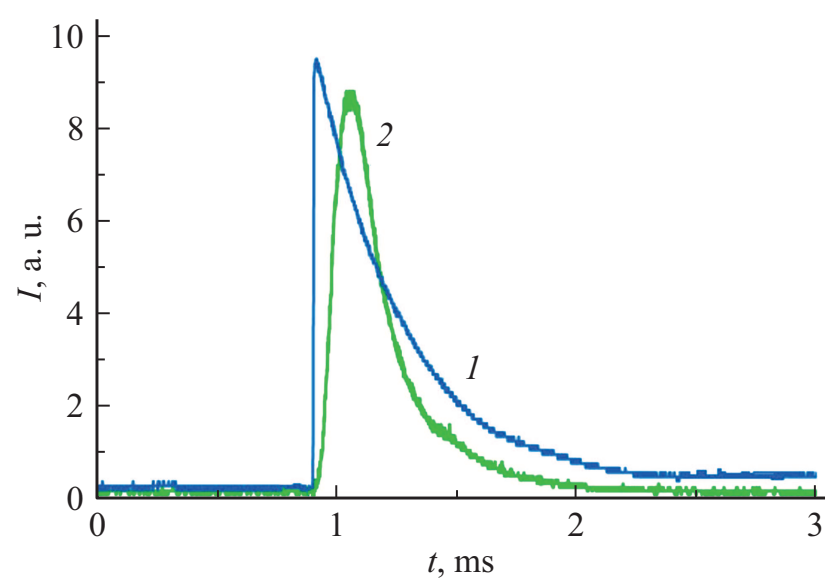

Рис. 3. Фотолюминесценция и механолюминесценция композита на основе прозрачного в видимой области спектра клея и порошка люминофора $\mathrm{SrAl}_{2} \mathrm{O}_{4}: \mathrm{Eu}^{2+}, \mathrm{Dy}^{3+}$, возбуждаемые лазерным импульсом $(\lambda=355 \mathrm{~nm}, \tau=8 \mathrm{~ns})(1)$ и механическим ударом (2).

в то время как в механолюминесцирующем слое они достаточно надежно проявляются.

Кинетика свечения фотолюминесценции и механолюминесценции полученного композита, возбуждаемых соответственно лазерным импульсом $(\lambda=355 \mathrm{~nm}$, $\tau=8 \mathrm{~ns}$ ) и ударом металлического шарика, показаны на рис. 3 .

Таким образом, проведены исследования процесса разрушения материалов из стекла марки К8 при воздействии механического ударника. Впервые предложено использование композиционного механолюминесцирующего материала на основе клея и мелкодисперсного порошка люминофора $\mathrm{SrAl}_{2} \mathrm{O}_{4}: \mathrm{Eu}^{2+}, \mathrm{Dy}^{3+}$ для визуализации процесса разрушения при ударе. Показано, что напряжения и трещины, возникающие в материале в процессе разрушения при ударе, достаточно полно и надежно визуализируются механолюминесцирующим слоем, нанесенным на поверхность исследуемого материала.

\section{Благодарности}

Автор выражает благодарность А.Г. Шубному за проведение исследований структуры порошка $\mathrm{SrAl}_{2} \mathrm{O}_{4}$ : $\mathrm{Eu}^{2+}, \mathrm{Dy}^{3+}$ на сканирующем электронном микроскопе.

\section{Финансирование работы}

Исследование выполнено при финансовой поддержке РФФИ и Госкорпорации „Росатом“ в рамках научного проекта № 20-21-00066 и частичной поддержке Министерства науки и высшего образования в рамках выполнения работ по государственному заданию ФНИЦ „Кристаллография и фотоника“ РАН (в части получения новых наноматериалов и наноструктур для решения актуальных задач микро- и наноэлектроники и нанофотоники). 
Funding: The reported study was funded by RFBR and ROSATOM, project number 20-21-00066 and partialy supported by the RF Ministry of Science and Higher Education as a part of a State Task for the Federal Sciences Research Center „Crystallography and Photonics“ of Russian Academy of Sciences (in part of obtaining new nanomaterials and nanostructures for solving urgent problems of micro- and nanoelectronics and nanophotonics).

\section{Конфликт интересов}

Автор заявляет, что у него нет конфликта интересов.

\section{Список литературы}

[1] J.C. Zhang, X. Wang, G. Marriott, C.N. Xu, Prog. Mater. Sci., 103, 678 (2019). DOI: 10.1016/j.pmatsci.2019.02.001

[2] D. Tu, C.N. Xu, S. Kamimura, Y. Horibe, H. Oshiro, L. Zhang, Y. Ishii, K. Hyodo, G. Marriott, N. Ueno, X.G. Zheng, Adv. Mater., 32, 1908083 (2020). DOI: 10.1002/adma.201908083

[3] H. Lv, Z. Pan, Y. Wang, J. Lumin., 209, 129 (2019). DOI: org/10.1016/j.jlumin.2019.01.026

[4] H. Sun, Y. Zhao, C. Wang, K. Zhou, C. Yan, G. Zheng, J. Huang, K. Dai, C. Liu, C. Shen, Nano Energy, 76, 105035 (2020). DOI: org/10.1016/j.nanoen.2020.105035

[5] C. Wang, L. Dong, D. Peng, C. Pan, Adv. Intell. Syst., 1, 1900090 (2019). DOI: 10.1002/aisy.201900090

[6] L. Liu, C.N. Xu, A. Yoshida, D. Tu, N. Ueno, S. Kainuma, Adv. Mater. Technol., 4, 1800336 (2018). DOI: $10.1002 / \mathrm{admt} .201800336$

[7] A. Feng, P.F. Smet, Materials, 11, 484 (2018). DOI: $10.3390 / \mathrm{ma1} 1040484$

[8] B.P. Chandra, V.K. Chandra, P. Jha, Physica B, 463, 62 (2015).

[9] P. Jha, B.P. Chandra, Luminescence, 32, 171 (2017). https://doi.org/10.1002/bio.3162

[10] A.F. Banishev, A.A. Banishev, Int. J. Mod. Phys. B, 33, 1950367 (2019). DOI: 10.1142/S02179792195036614

[11] А.Ф. Банишев, А.А. Банишев, Письма в ЖТФ, 45 (10), 3 (2019). DOI: 10.21883/PJTF.2019.10.47746.17737

[12] J.J. Joos, K. Korthout, L. Amidani, P. Glatzei, D. Poelman, P.F. Smet, Phys. Rev. Lett., 125, 033001 (2020). DOI: 10.1103/PhysRevLett.125.033001

[13] A.I. Azad, M.R. Rahimi, G.J. Yun, Smart Mater. Struct., 25, 095032 (2016).

[14] I.P. Sahu, D.P. Bisen, N. Brahme, R.K. Tamrakar, J. Mater. Sci.: Mater. Electron., 26, 10075 (2015).

DOI: $10.1007 / \mathrm{s} 10854-015-3691-\mathrm{y}$ 